\title{
ACIR
}

Selected Papers of \#AolR2019:

The $20^{\text {th }}$ Annual Conference of the

Association of Internet Researchers

Brisbane, Australia / 2-5 October 2019

\section{API AND BEYOND: DETECTING COORDINATED BEHAVIOURS IN FACEBOOK INTERACTIONS AROUND POLITICAL NEWS STORIES}

\author{
Fabio Giglietto \\ University of Urbino Carlo Bo
}

Nicola Righetti

University of Urbino Carlo Bo

\author{
Giada Marino \\ University of Urbino Carlo Bo
}

This proposal is a follow-up of the project "Mapping Italian News Media Political Coverage in the Lead-up to 2018 General Election" (MINE). MINE aimed at creating a comprehensive map of the political news coverage created by the Italian online news media in the lead-up to 2018 general election. The project collected 84,815 news stories published by over 4,000 news sources shared on Facebook in the six months before the elections, monitoring in real time their engagement (number of shares, reactions and comments).

The final report of the project (Giglietto et al., 2018) highlighted how the populist narrative dominated the news (both in terms of volume of coverage and Facebook engagement) in the run-up to the Italian elections, and pinpointed the diverging patterns of Facebook interactions employed by different partisan communities (particularly those related to populist parties) to amplify the reach of the content aligned with their worldview by sharing news stories on social media, while trying to reframe, through comments, the negative coverage of the party they support. These insights led to further questions concerning the nature of the observed diverging patterns of Facebook interactions around political news. In particular, we wondered if the observed patterns were the result of a spontaneous grassroots effort, i.e. the consequence of a combination of non-coordinated individual actions, or instead of a strategically organized attempt to manipulate the online news media landscape in order to game platforms algorithms in support of specific viewpoints, candidates and parties.

Despite several studies have already pointed out the systematic use of bots and fake accounts in electoral campaigns (Bastos \& Marcea, 2018; Bessi \& Ferrara, 2016; Tucker et al., 2018), few studies directly focused on strategically coordinated online behaviours aimed at hacking the attention economy on Facebook.

Social media like Facebook have increasingly become sources of information for the citizens (e.g. Pew Research Center, 2018). It is thus crucial to understand to what extent social media users are exposed on Facebook to news-stories amplified or 


\section{AOR}

Selected Papers of \#AolR2019:

The $20^{\text {th }}$ Annual Conference of the Association of Internet Researchers

Brisbane, Australia / 2-5 October 2019

criticized through authentic and inauthentic coordinated behaviour (Gleicher, 2018) with the aim of twisting the perception of public opinion and, in turn, influence the behaviour of professional journalists and other citizens.

Data originally collected for MINE during 2018 via publically available Facebook API proved useful to identify the patterns, but fall short of providing compelling evidence on the nature of these behaviours. In order to shed some light on this question, we thus requested and obtained access to two additional datasets directly provided by Facebook and made available through the Social Science One (SSO) initiative ${ }^{1}$. Informed by the results of MINE 2018 project (Giglietto et al., 2018; Giglietto, Righetti, Marino \& Rossi, 2019) and by the existing literature on echo-chambers (Garrett, 2009; Sunstein, 2001; Vaccari, 2013), news preferential exposure (Bakshy et al., 2015; Messing \& Westwood, 2014;), attention economy and strategic amplification (Philips, 2018; Webster, 2014; Zhang et al., 2017), we thus designed a set of hypothesis articulated in three areas:

A) The first area pertains to the social infrastructure. The main hypothesis is that an organized effort may have employed an existing network of Facebook pages and groups aimed at facilitating certain collective behaviour. Higher percentages of news-stories shares performed by pages and groups (as opposed to personal profiles) may thus be a sign of a coordinated behaviour;

B) The second area employs insularity (a measure - developed for MINE - of the extent to which an online news source is exclusively shared by actors affiliated to a specific online partisan community) to understand at what extent shares and comments without-clicks (interactions performed on a shared news-story based on the information displayed by Facebook - title, part of the blurb - rather than after reading the article) are affected by this characteristic of the news source. Higher percentages of interactions-without-click on overall interactions may be a sign of coordinate behaviour;

C) Lastly, the exposure to news stories area addresses the frequency and typology of views of certain content. Both Facebook algorithms and the structure of the user's social networks affect exposure. We hypothesize that due to the combination of these factors, news-stories published by insular online news sources are shown more frequently to a single user and more prominently (top news-feed slot) than other news stories.

In this paper, the authors present the measures developed to address the research questions articulated in the three areas with respective findings. Although based on 2018 general election and 2019 European election in Italy, the results will be discussed in a broader context with the aim to shed light on the opportunities provided by SSO datasets to identify coordinated inauthentic behaviours on Facebook. The research findings are presented in the report "Understanding Coordinated and Inauthentic Link Sharing Behavior on Facebook in the Run-up to 2018 General Election and 2019 European Election in Italy" (Giglietto, Righetti \& Marino, 2019; available at 10.31235/osf.io/3jteh).

\footnotetext{
${ }^{1}$ URL Share Dataset and CrowdTangle API described in depth at https://socialscience.one/.
} 


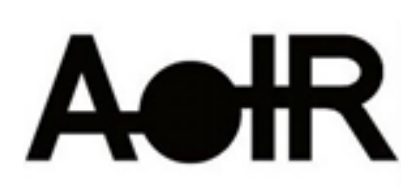

Selected Papers of \#AolR2019:

The $20^{\text {th }}$ Annual Conference of the Association of Internet Researchers

Brisbane, Australia / 2-5 October 2019

\section{References}

Bakshy, E., Messing, S., \& Adamic, L. A. (2015). Exposure to ideologically diverse news and opinion on Facebook. Science, 348(6239), 1130-1132.

Bastos, M., \& Mercea, D. (2018). The public accountability of social platforms: lessons from a study on bots and trolls in the Brexit campaign. Philosophical Transactions of the Royal Society A: Mathematical, Physical and Engineering Sciences, 376(2128), 20180003.

Bessi, A., \& Ferrara, E. (2016). Social bots distort the 2016 US Presidential election online discussion.

Faris, R., Roberts, H., Etling, B., Bourassa, N., Zuckerman, E., \& Benkler, Y. (2017). Partisanship, Propaganda, and Disinformation: Online Media and the 2016 U.S. Presidential Election. Retrieved from https://papers.ssrn.com/sol3/papers.cfm?abstract_id=3019414

Garrett, R. K. (2009). Echo chambers online?: Politically motivated selective exposure among Internet news users. Journal of Computer-Mediated Communication, 14(2), 265-285.

Giglietto, F., Iannelli, L., Rossi, L., Valeriani, A., Righetti, N., Carabini, F., ... \& Zurovac, E. (2018). Mapping Italian News Media Political Coverage in the Lead-Up to 2018 General Election. Available at SSRN 3179930.

Giglietto, F., Righetti, N., Marino, G., \& Rossi, L. (2019). Multi-party media partisanship attention score. Estimating partisan attention of news media sources using Twitter data in the lead-up to 2018 Italian election. Comunicazione politica, 20(1), 85-108.

Giglietto, F., Righetti, N., \& Marino, G. (2019, September 20). Understanding Coordinated and Inauthentic Link Sharing Behavior on Facebook in the Run-up to 


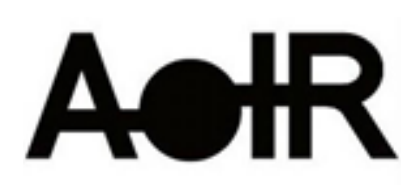

Selected Papers of \#AolR2019:

The $20^{\text {th }}$ Annual Conference of the Association of Internet Researchers

Brisbane, Australia / 2-5 October 2019

2018 General Election and 2019 European Election in Italy.

https://doi.org/10.31235/osf.io/3jteh

Gleicher, N. (December 6, 2018). Coordinated Inauthentic Behavior Explained.

Available at Facebook Newsroom:

https://newsroom.fb.com/news/2018/12/inside-feed-coordinated-inauthentic-behavior I

Messing, S., \& Westwood, S. J. (2014). Selective exposure in the age of social media: Endorsements trump partisan source affiliation when selecting news online. Communication Research, 41(8), 1042-1063.

Marwick, A., \& Lewis, R. (2017). Media manipulation and disinformation online. New York: Data \& Society Research Institute.

Pew Research Center. (2001). Americans Still Prefer Watching to Reading the News - and Mostly Still Through Television. Annual Report. Washington, DC:. Amy Mitchell.

Phillips, W. (2018). The Oxygen of Amplification. New York: Data \& Society Research Institute.

Sunstein, C. R. (2001). Echo chambers: Bush v. Gore, impeachment, and beyond. Princeton, NJ: Princeton University Press.

Tucker, J., Guess, A., Barberá, P., Vaccari, C., Siegel, A., Sanovich, S., Stukal, D., \& Nyhan, B. (2018). Social media, political polarization, and political disinformation: A review of the scientific literature. Available at SSRN:

https://ssrn.com/abstract=3144139

Vaccari, C. (2013). From echo chamber to persuasive device? Rethinking the role of the Internet in campaigns. New Media \& Society, 15(1), 109-127.

Webster, J.G. (2014) The Marketplace of Attention: How Audiences Take Shape in a Digital Age. Cambridge, MA: The MIT Press. 


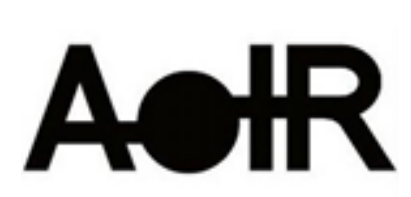

Selected Papers of \#AolR2019:

The $20^{\text {th }}$ Annual Conference of the

Association of Internet Researchers

Brisbane, Australia / 2-5 October 2019

Zhang, Y., Wells, C., Wang, S., \& Rohe, K. (2017). Attention and amplification in the hybrid media system: The composition and activity of Donald Trump's Twitter following during the 2016 presidential election. New Media \& Society, 1461444817744390. 